\title{
DFT investigation of molybdenum (oxo)carbide formation from $\mathrm{MoO}_{3}$
}

\author{
Dorota Rutkowska-Zbik • Robert Grybos • \\ Renata Tokarz-Sobieraj
}

Received: 28 July 2011/ Accepted: 20 December 2011/Published online: 26 May 2012

(C) The Author(s) 2012. This article is published with open access at Springerlink.com

\begin{abstract}
The present paper summarizes theoretical investigations of geometry and electronic structure of (oxo)carbide, whose formation is modeled by systematic replacement of lattice oxygen atoms in $\mathrm{MoO}_{3}$ by carbon atoms or by $\mathrm{CH}_{2}$ groups. Both, in bulk and in the small surface cluster, the formation of molybdenum (oxo)carbide is accompanied by by-products observed in experiment, namely $\mathrm{C}_{2}$ species and $\mathrm{CO}$. The present theoretical studies reveal that these are formed without reaction barrier, even though in bulk the atom mobility is limited. The thermodynamic considerations based on the obtained DFT results indicate that the process of $\mathrm{MoO}_{3}$ reduction to yield (oxo)carbides is endoenergetic and there is no synergy between the amount of carbon already introduced to the system and the energetic cost of replacing oxygen atoms by $\mathrm{CH}_{2}$.
\end{abstract}

Keywords $\mathrm{MoO}_{3} \cdot \mathrm{Mo}_{2} \mathrm{C} \cdot \mathrm{ZSM}-5$.

Aromatization of methane $\cdot$ DFT

\section{Introduction}

The growing consumption of energy is one of the challenges faced by the modern world. On the one hand, the effort is made to search for new sources of energy; while on the other hand, the way the conventional sources are

We would like to dedicate this paper to Professor Malgorzata Witko who introduced us to the world of quantum chemistry calculations.

D. Rutkowska-Zbik · R. Grybos · R. Tokarz-Sobieraj ( $\square)$ Jerzy Haber Institute of Catalysis and Surface Chemistry, Polish Academy of Sciences, ul. Niezapominajek 8, 30-239 Kraków, Poland

e-mail: nctokarz@cyf-kr.edu.pl exploited is further developed. Within the latter approach, new processes of hydrocarbon conversion are investigated. One such process is non-oxidative conversion of methane to aromatics, catalyzed by $3-5 \% \mathrm{MoO}_{3}$ in ZSM-5 type zeolite [1-11]. During the catalytic process, methane reduces $\mathrm{MoO}_{3}$ phase to yield $\mathrm{MoO}_{3-x}$ and further molybdenum (oxo)carbide [2, 12]. It seems that molybdenum (oxo)carbide is the active phase responsible for methane dehydrogenation and conversion to ethylene, which, in turn, is aromatized inside the channels of the zeolite $[5,7$, 13]. It is postulated that molybdenum species are present on both, outer surface and inside the pores of the zeolitic support [14], but, despite numerous catalytic and physicochemical studies, the nature of the formed carbonaceous species is not clear [13]. The experimental investigations suggest that molybdenum phase is highly dispersed $[2,3,6$, 13, 15]. EXAFS studies provide one with the Mo-Mo distance which varies from $3.09 \AA$ (in fresh, calcined catalyst) to $4.10 \AA$ (used catalyst), and $\mathrm{Mo}-\mathrm{X}(\mathrm{X}=\mathrm{C}$ or $\mathrm{O})$ distance falling between 1.63 and $1.91 \AA$ (fresh) and 2.00-2.82 $\AA$ (used) [3]. The existence of carbene-like species $\left(\mathrm{CH}_{2}=\mathrm{Mo}\right)$ is postulated $[5,15]$.

In the existing theoretical investigations, the structure of the catalyst based on Mo/zeolite refer mainly to pure molybdenum structures: either oxides or carbides [16-20]. Consequently, the models employed thus far for studying this type of molybdenum-based catalyst describe Mo environment as containing oxygen atoms or carbon atoms. The structure of the catalyst for the methane activation based on Mo/zeolite has been studied for the model consisting of single Mo center in form of $\mathrm{CH}_{2}=\mathrm{Mo}\left(\mathrm{CH}_{3}\right)_{3}$ bound to $\mathrm{SiO}_{3}-\mathrm{O}-\mathrm{AlO}_{3}$ fragment, representing the zeolitic framework [21]. Similarly, $\mathrm{MoO}\left(\mathrm{CH}_{2}\right)$ site in ZSM-5 zeolite has been described in relation to its activity in metathesis [22]. $\mathrm{Mo}_{2} \mathrm{O}_{5}$ cluster has been investigated by 
Zhou et al. [23], while larger $\mathrm{Mo}_{3} \mathrm{O}_{9}$ system as the active site has been chosen by Fu et al. [24]. Up to the best of our knowledge, the structure of molybdenum (oxo)carbides has not been characterized by theoretical methods so far.

The aim of the present studies is to characterize the geometry and electronic structure of possible oxocarbide phase of the $\mathrm{MoO}_{3} / \mathrm{ZSM}-5$ catalyst in an aid to help to elucidate structure-activity relationship. Our studies refer mainly to the induction period of the catalytic process during which methane is passed over the catalyst and is believed to reduce $\mathrm{MoO}_{3}$ to $\mathrm{MoO}_{3-x}$ and further the $\mathrm{MoO}_{x} \mathrm{C}_{y}$ [2, 12]. As by-products of the reduction of molybdenum oxide, $\mathrm{C}_{2}$ hydrocarbons, $\mathrm{CO}, \mathrm{CO}_{2}, \mathrm{H}_{2} \mathrm{O}$, and $\mathrm{H}_{2}$ are observed $[2,4,13,25]$. In view of the fact that experimental studies of the active phase of the catalyst in course of the catalytic process are strictly limited, these observations are used to validate our theoretical results.

\section{Methodology}

In order to investigate the possible phases of (oxo)carbides the density functional theory (DFT) is applied by gradually replacing $\mathrm{MoO}_{3}$ lattice oxygen atoms by carbon atoms and performing full geometry optimization of the systems. In such a way the structural changes induced by the modification of chemical composition of the catalyst might be observed. These are purely static calculations, aiming at the determination of the stable geometry structures. Although no reaction pathways are considered, the application of the geometry minimization algorithms ensures that the resulting species are formed without crossing energy barriers.

The total charge of all studied structures is kept constant and equal to zero to avoid the problem of non-balanced charge in the calculations. The drawback of such an approach is the possibility for the metal cations to be reduced. However, the reduction of the catalytic system during (oxo)carbides formation is often evoked by experiment $[2,12]$.

The transformations of the solid phase are modeled within periodic approach taking into account the bulk structure. This part of the calculations is done with VASP code [26-28] using PW91 functional [29, 30]. Electrons are described by PAW $[31,32]$ with a default cut-off energy of $400 \mathrm{eV}$. The geometry optimization was done within conjugate-gradient algorithm with the gradient threshold of $0.01 \mathrm{eV} / \AA$. The structure is modeled using supercell containing four molybdenum atoms-see Fig. 1a.

The transformations of the small surface clusters, which mimic the active phase deposited on the zeolitic support, are studied with cluster approach. The initial cluster (shown in Fig. 1b), containing two molybdenum octahedrons, is cut out of the lattice structure of $\mathrm{MoO}_{3}$ [33]. The

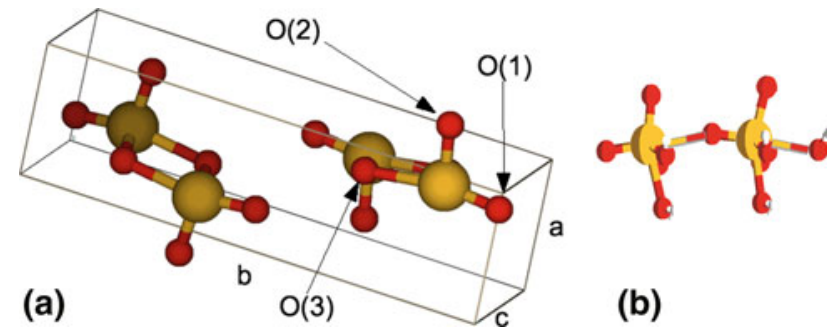

Fig. 1 Structural models applied for the present studies: a $\mathrm{MoO}_{3}$ supercell representing oxide bulk and $\mathbf{b}$ super-molecule representing small surface cluster

terminal oxygen atoms are saturated by hydrogen atoms, according to the procedure described elsewhere [19, 34]. The small size of the cluster chosen for the present studies follows from the experimental indications [2, 3, 6, 13, 15].

The cluster calculations are done with Turbomole program [35] using non-hybrid PBE functional [30, 36-38] with resolution-of-identity approach [39, 40]. All electron def-TZVP basis sets [41] are applied for all atoms in the system. Here, the geometry optimization proceeds according to quasi Newton-Raphson method with energy change threshold of $10^{-6} \mathrm{Ha}$ and geometry gradient threshold of $10^{-3} \AA$.

\section{Results and discussion}

The initial catalyst contains $\mathrm{MoO}_{3}$ as a precursor of the active phase. Its geometry and electronic properties are already described in literature-compare e.g. Ref. [16, 19]. Although it is not the aim of the present study to describe its properties, the key structural parameters of the oxide are summarized in Table 1 to compare with the reported results. In the bulk structure of $\mathrm{MoO}_{3}$ there exist three types of oxygen atoms: singly, doubly and triply coordinated to the neighboring metal ions. All metal-oxygen bonds are of a mixed ionic and covalent character. The nucleophilicity of oxygen sites, expressed as Mulliken charges, scales with their coordination number.

Table 1 Structural parameters of $\mathrm{MoO}_{3}$

\begin{tabular}{lll}
\hline Bond lengths & Exp $[\AA]$ & Theory $[\AA]$ \\
\hline Mo-O(1) & 1.67 & 1.70 \\
$\mathrm{Mo}-\mathrm{O}(2)$ & 1.73 & 1.77 \\
$\mathrm{Mo}-\mathrm{O}(3)$ & 1.95 & 1.95 \\
$\mathrm{Mo}-\mathrm{O}(2)$ long & 2.25 & 2.22 \\
$\mathrm{Mo}-\mathrm{O}(3)$ long & 2.33 & 2.37
\end{tabular}

Experimental results: bulk structure of $\mathrm{MoO}_{3}$, orthorhombic system, Pbnm, space group (\#62), $a=3.963 \AA$, $b=13.855 \AA, c=3.696 \AA$, $\alpha=\beta=\gamma=90^{\circ}$ [33] 
Transformation of bulk $\mathrm{MoO}_{3}$

The formation of molybdenum (oxo)carbide phase is studied by the gradual replacement of lattice oxygen by carbon atoms and subsequent geometry optimization of the systems.

First, a single substitution is considered. There are three scenarios for such a process: carbon atom may replace one of the three structurally different oxygen atoms-singly coordinated $\mathrm{O}(1)$, doubly coordinated $\mathrm{O}(2)$, or triply coordinated $\mathrm{O}(3)$-see Fig. 2. The comparison of the total energies of the systems reveals that the structure with the $\mathrm{O}(2)$-type oxygen center substituted is the most stable. Substitution of $\mathrm{O}(3)$ center requires $20 \mathrm{~kJ} / \mathrm{mol}$ more, while substitution of $\mathrm{O}(1)$ is the least probable and requires $56 \mathrm{~kJ} / \mathrm{mol}$ more energy.

Second, a double substitution is investigated. Within the supercell used in the present studies, there are 21 possibilities for replacement of two oxygen atoms-all of them are investigated. The resulting structures are presented in Fig. 3. As is seen from the picture, a considerable rearrangement of molybdenum oxide structure is found in a number of systems. This is manifested in $\mathrm{CO}$ and $\mathrm{CC}$ species formation. The formation of $\mathrm{CC}$ groups is observed when two carbon atoms are introduced at sites $\mathrm{O}(1)$ and $\mathrm{O}(3)$ at an initial distance of $3.41 \AA$. Formation of $\mathrm{CO}$ occurs in several other cases, as shown in Fig. 3. In the case when two carbon atoms replace two $\mathrm{O}(1)$ atoms attached to neighboring molybdenum atoms, rather extensive reconstruction of the $\mathrm{MoO}_{3}$ structure is observed.

It should be stressed here that $\mathrm{CO}$ and $\mathrm{CC}$ species are formed without any reaction barrier, even though the mobility of atoms in the bulk is limited.

The analysis of total energies of the studied systems (Fig. 4) shows that there is no clear correlation between the

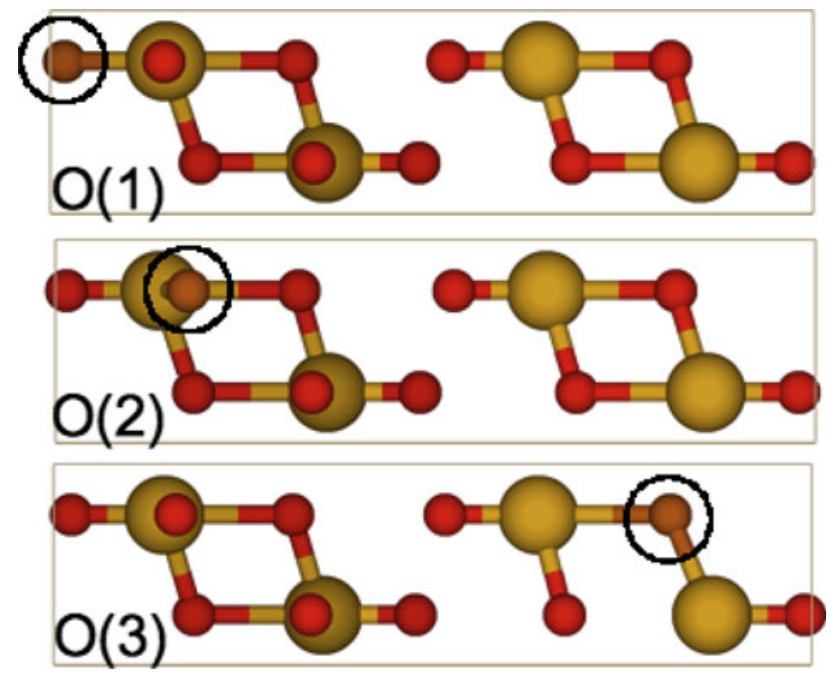

Fig. 2 Three possibilities for single oxygen substitution in bulk stability of the resulting (oxo)carbide structure and the optimized distance between the two carbon atoms introduced into the bulk. At distances over $3 \AA$ the energies are basically independent of the $\mathrm{C}-\mathrm{C}$ distance. Below $3 \AA$, the stability is proportional to the $\mathrm{C}-\mathrm{C}$ distance, except for the structure at $2.11 \AA$, discussed below. Results show that the $\mathrm{C}-\mathrm{C}$ distance is not the decisive factor in determining the stability, others being the mutual arrangement and type of the oxygen centers replaced by carbon. The most stable structure (apart from those in which $\mathrm{C}-\mathrm{C}$ or $\mathrm{C}-\mathrm{O}$ bonds were formed) is the one with the shortest $\mathrm{C}-\mathrm{C}$ distance $(2.11 \AA)$ where two neighboring $\mathrm{O}(2)$-type oxygen centers were replaced by carbon. From the initial distance of $3.10 \AA$ they were pulled together, while still remaining as the bridging atoms between two molybdenum atoms. Despite the distance being larger than the longest covalent $\mathrm{C}-\mathrm{C}$ bond (1.54 $\AA$ in diamond), there is a clear attraction, that stabilizes the structure.

The creation of $\mathrm{CO}$ bonds contributes greatly to the structure stabilization. The most stable structure overall, is the one where the largest reconstruction of the bulk structure occurs. Replacing two O(1)-type oxygen atoms with carbon causes one of the Mo "dimers" to tilt by ca. $45^{\circ}$ accompanied by the creation of two Mo-C-O-Mo bridges. This reconstruction is also barrier-less.

\section{Transformation of $\mathrm{MoO}_{3}$ surface clusters}

Similarly, the formation of (oxo)carbides is studied for the small surface clusters of $\mathrm{MoO}_{3}$. Here, the oxygen atoms are replaced not only by carbon atoms, but also by methylene $\left(\mathrm{CH}_{2}\right)$ groups. While the substitution by carbon is expected to be consistent with the methodology used to examine the effects of the transformation in bulk, the substitution by $\mathrm{CH}_{2}$ might appear more suitable for the description of the surface by ensuring the proper saturation of the atoms. Moreover, the presence of $\mathrm{Mo}=\mathrm{CH}_{2}$ species is postulated by the experiment $[5,15]$.

In order to model the active phase-support (ZSM-5) interaction, hydrogen atoms bound to oxygen atoms are frozen. The resulting geometry and energetic parameters derived from the cluster calculations are presented in Fig. 5.

First, the substitution of lattice oxygen atoms by $\mathrm{CH}_{2}$ group is examined. When $\mathrm{O}(1)$ is substituted, a $1.92 \AA$ molybdenum-carbon bond is formed, accompanied by a slight shrink to $4.23 \AA$ of the distance between two molybdenum ions. Such a structure is by $87 \mathrm{~kJ} / \mathrm{mol}$ more favorable than $\mathrm{O}(2)$ substitution. In the latter case, the bulky $\mathrm{CH}_{2}$ moiety is placed in between two molybdenum ions and shifts them apart by $0.54 \AA$ as compared to the starting structure. The introduced carbon binds to only one molybdenum with a bond of $1.71 \AA$. 

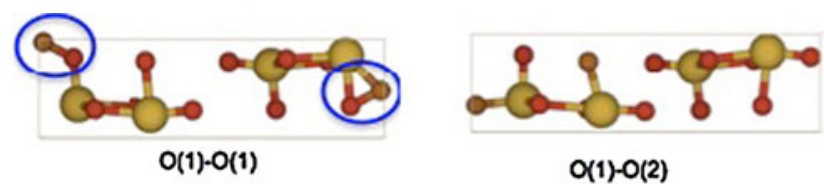

O(1)-O(2)
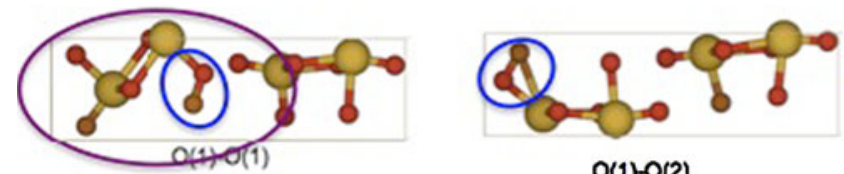

O(1)-O(2)

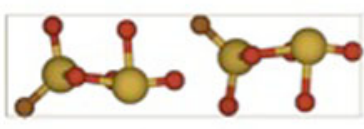

O(1)-O(1)

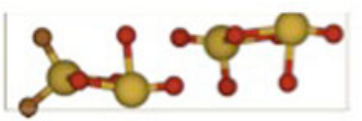

O(1)०(2)

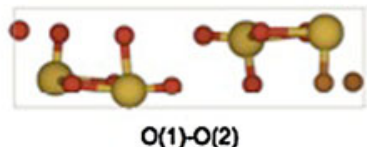

O(1)-O(2)

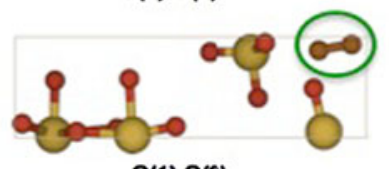

$O(1)-O(3)$

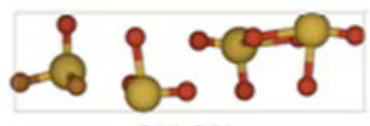

$O(1)-O(3)$

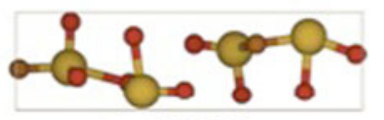

$O(1)-0(3)$

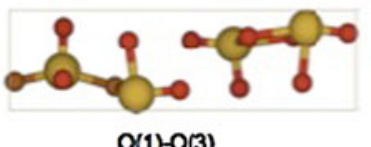

O(1)-O(3)
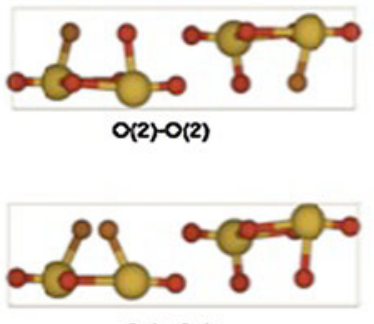

O(2)-(2)

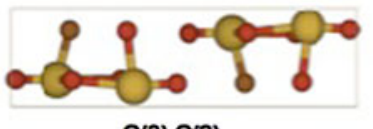

O(2)-O(2)

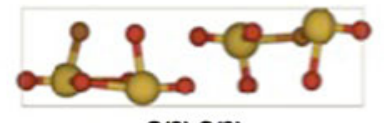
O(2)-O(3)

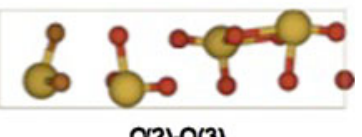

O(2)-O(3)

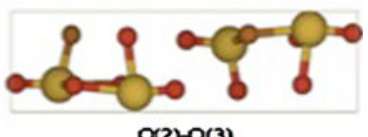

O(2) $O(3)$

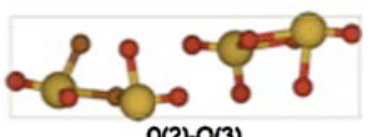

$\mathrm{O}(2)-\mathrm{O}(3)$

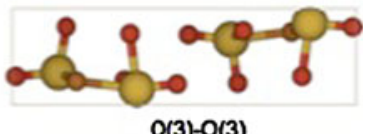

O(3)-O(3)

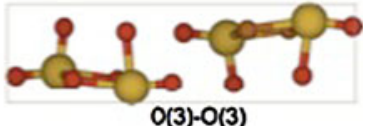

O(3)-O(3)

C-C formation

C-O formation

reconstruction

O(3)-(3)

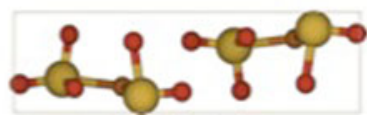

Fig. 3 Structures resulting form the double substitution in bulk

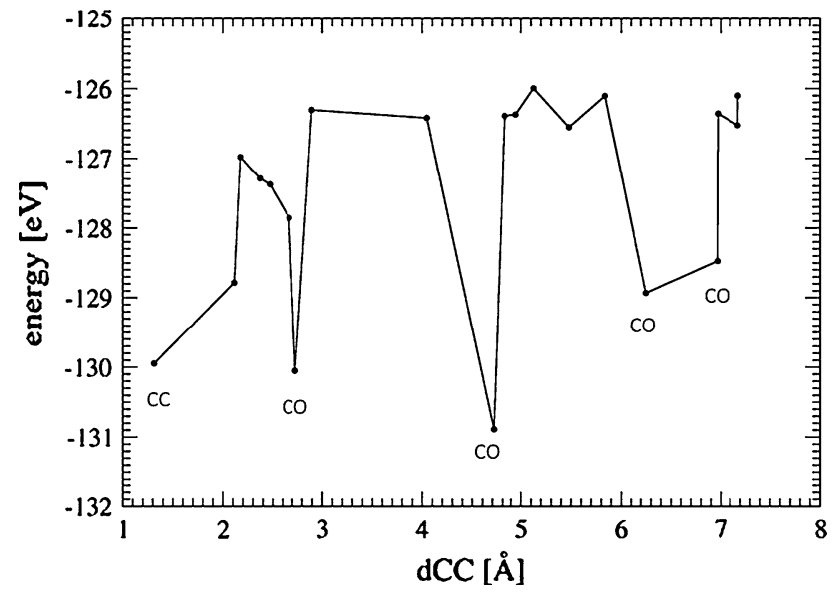

Fig. 4 Relationship between the $\mathrm{C}-\mathrm{C}$ distance and total energy of the system

When the carbon atom is introduced in $\mathrm{O}(2)$ position, it induces geometric changes of the whole cluster. It attracts one of the $\mathrm{O}(1)$ atoms and forms a $\mathrm{CO}$ species which nonequivalently interacts with both Mo ions. One may distinguish $\sigma$-type bond of $1.97 \AA$ with one Mo and a $\pi$-interaction between $\mathrm{CO}$ and the second Mo. The latter is further reflected by the $\mathrm{C}-\mathrm{O}$ bond length being $0.14 \AA$ longer than the $\mathrm{C}-\mathrm{O}$ bond in an isolated carbon monoxide molecule calculated at the same level. Such an interaction and formation of bonds with both molybdenum atoms result in the decrease of molybdenum-molybdenum distance by $0.33 \AA$.

The geometric parameters of the structure in which two $\mathrm{O}(1)$ oxygen atoms are replaced by $\mathrm{CH}_{2}$ are very similar to those obtained for singly substituted $\mathrm{O}(1)$ cluster: both Mo-C carbons are of the same length, and Mo-Mo distance is only $0.01 \AA$ longer than in the reference structure. The structure in which two $\mathrm{CH}_{2}$ replace $\mathrm{O}(1)$ and $\mathrm{O}(2)$ is less stable by $32 \mathrm{~kJ} / \mathrm{mol}$. Here, two $\mathrm{CH}_{2}$ groups are twisted by $90^{\circ}$ one with respect to another. Due to the steric interactions, Mo-C bonds are not equivalent: the bond which lies in the Mo-Mo direction is shorter by $0.06 \AA$ than the one pointing out of surface cluster. Similarly, the distance between both metal ions is expanded by $0.29 \AA$ with respect to its value in the starting structure.

Next, a situation in which $\mathrm{O}(1)$ is replaced by $\mathrm{CH}_{2}$ and $\mathrm{O}(2)$ by $\mathrm{C}$ is considered. Geometry relaxation leads to the recombination of both carbonaceous species yielding $\mathrm{CCH}_{2}$ moiety bound to one molybdenum atom via both carbon atoms. The $\mathrm{C}-\mathrm{C}$ distance is equal to $1.42 \AA-\mathrm{a}$ value which is usually attributed to the bonding between $\mathrm{sp}^{2}$ and $\mathrm{sp}$ carbons.

Two structures are considered for three oxygen atoms substitution: one in which two $\mathrm{O}(1)$ and one $\mathrm{O}(2)$ species 
Fig. 5 Structural parameters of surface clusters of (oxo)carbides: a single substitution, $\mathbf{b}$ double substitution, and $\mathbf{c}$ triple substitution

(a)

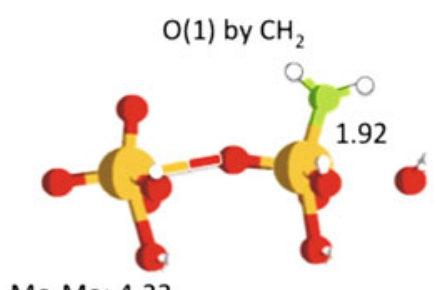

Mo-Mo: 4.23

$\Delta \mathrm{E}=0.0 \mathrm{~kJ} / \mathrm{mol}$

$\mathrm{O}(2)$ by $\mathrm{CH}_{2}$

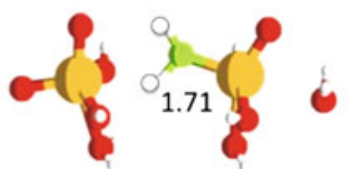

Mo-Mo: $4.83 \quad \Delta E=+87 \mathrm{~kJ} / \mathrm{mol}$

(b)

$\mathrm{O}(1)$ and $\mathrm{O}(1)^{*}$ by $\mathrm{CH}_{2}$

$\mathrm{O}(1)$ by $\mathrm{CH}_{2}, \mathrm{O}(2)$ by $\mathrm{C}$

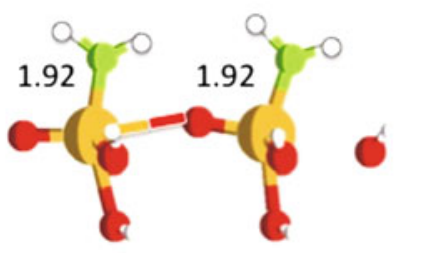

Mo-Mo $4.30 \quad \Delta E=0.0 \mathrm{~kJ} / \mathrm{mol}$

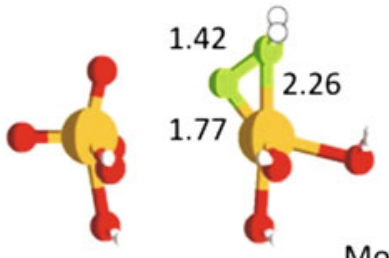

Mo-Mo 4.51

$\mathrm{O}(1)$ and $\mathrm{O}(2)$ by $\mathrm{CH}_{2}$

Mo-Mo 4.58
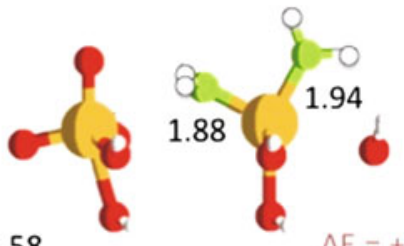

(c)

$2 \times \mathrm{O}(1)$ and $\mathrm{C}(2)$ by $\mathrm{CH}_{2}$

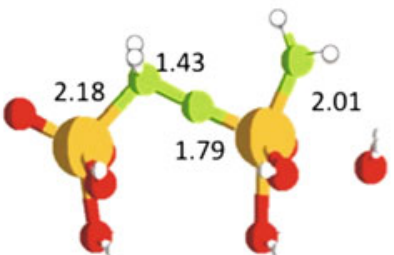

Mo-Mo 4.35
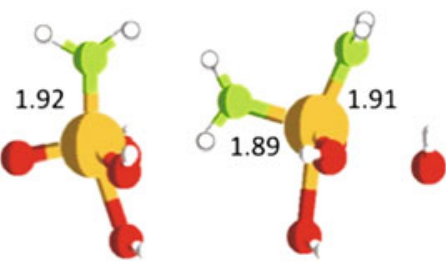

Mo-Mo 5.01 are replaced by $\mathrm{CH}_{2}$ and the second in which two $\mathrm{O}(1)$ and one $\mathrm{O}(2)$ are changed for $\mathrm{CH}_{2}$ and $\mathrm{C}$, respectively. In the first case one may see that all Mo- $\mathrm{C}$ bonds have similar lengths. As in the previously described cases, the bulky methylene group pushes molybdenum ions apart by $0.72 \AA$. In the second case, $\mathrm{C}$ atom reacts with $\mathrm{CH}_{2}$ group yielding $\mathrm{CCH}_{2}$ species, bridging two molybdenum ions. At the same time, the Mo- $\mathrm{CH}_{2}$ bond is elongated by $0.1 \AA$ with respect to its typical value in other complexes.

In addition, models of fully carbon-substituted molybdenum systems were also considered. A number of cases is considered here, with all oxygen atoms, which lie in plane of or above Mo ions, changed for carbon-containing species, and the only remaining oxygen atoms are representing 
the zeolite structure (compare Fig. 6). First, a situation in which $\mathrm{O}(1)$ atoms are replaced by $\mathrm{CH}_{2}, \mathrm{O}(2)$ by $\mathrm{C}$, and the rest by $\mathrm{CH}_{3}$ is examined. Similarly to the already described picture, $\mathrm{C}$ recombines with $\mathrm{CH}_{2}$ to form $\mathrm{CCH}_{2}$ species. The latter forms $\sigma$ bond with one Mo ion, and interacts by its $\pi$ electron system with the second one. One should note, however, that here the Mo-C bond may also have a contribution from $\pi$-orbitals. When all oxygen atoms are substituted by $\mathrm{CH}_{3}$ groups and only $\mathrm{O}(2)$ by $\mathrm{C}$, the Mo-CMo bond pattern becomes almost symmetric, and the bond between one of the molybdenum ion and zeolitic oxygen is practically broken. In both structures, Mo-Mo distance is elongated by 0.42 and $0.45 \AA$, respectively.

Next, a structure in which both $\mathrm{O}(1)$ and $\mathrm{O}(2)$ are replaced by $\mathrm{CH}_{2}$ is studied, while other oxygen atoms lying in plane of molybdenum ions are changed for $\mathrm{CH}_{3}$. Here, one of the methylene groups binds to $\mathrm{CH}_{3}$ moiety yielding $\mathrm{CH}_{2} \mathrm{CH}_{3}$ fragment which bounds to Mo ion. Its $\mathrm{C}-\mathrm{C}$ length corresponds to the typical $\mathrm{C}\left(\mathrm{sp}^{3}\right)-\mathrm{C}\left(\mathrm{sp}^{3}\right)$ bond. Such, a modification in chemical composition and induced structural rearrangements result in the drastic elongation of $\mathrm{Mo}-$ Mo bond distance. It is seen that both molybdenum ions drift apart by $2.07 \AA$.

Finally, a structure in which molybdenum ions are not coordinatively saturated is considered: in-plane oxygen atoms are replaced by $\mathrm{CH}_{3}$ groups, $\mathrm{O}(2)$ is changed for $\mathrm{CH}_{2}$, and both $\mathrm{O}(1)$ are removed. In this structure, the cluster is broken into two almost separate molybdenum species (Mo-Mo distance is equal to $6.71 \AA$ ).
Similarly to the results obtained for the bulk, the present calculations show a barrier-less formation of $\mathrm{CO}$ and $\mathrm{CCH}_{2}$ species. The latter may be viewed as precursors of ethylene or carbon deposit. These findings agree well with the experimental observation that during the initial phase of the reaction, $\mathrm{CO}$ and $\mathrm{C}_{2} \mathrm{H}_{4}$ are formed, and in the course of the catalytic process, the deposition of carbonaceous species is detected $[2,4,13,25]$. The elongation of calculated Mo$\mathrm{C} / \mathrm{O}$ and Mo-Mo distances along with the increasing content of carbon in the system is in line with the results from the EXAFS experiments [3]. While the computed Mo-X (where $\mathrm{X}=\mathrm{C}, \mathrm{O}$ ) bond lengths $(1.79-2.33 \AA$ ) are within the range given by the experiment (2.00-2.82 $\AA$ ), larger mismatch is found for the Mo-Mo distances. According to EXAFS predictions, Mo-Mo separation should fall within 3.09-4.10 A. The present theoretical calculations show that this distance is usually ca. $4 \AA$, but under certain conditions may increase up to $6.71 \AA$. The existing discrepancies between the theoretical and experimental Mo-Mo bond length values should be attributed to the fact that the adopted theoretical model neglects the zeolitic framework keeping the molybdenum atoms in close distance.

Reduction of $\mathrm{MoO}_{3}$ surface clusters by $\mathrm{CH}_{4}$

Next, the thermodynamics of the reduction of $\mathrm{MoO}_{3}$ (represented by the surface clusters) by $\mathrm{CH}_{4}$ is considered. Such a reaction occurs in the initial phase of the catalytic process, where methane is flown over $\mathrm{MoO}_{3} / \mathrm{ZSM}-5$ [2, 4,
Fig. 6 Fully substituted models of molybdenum carbides

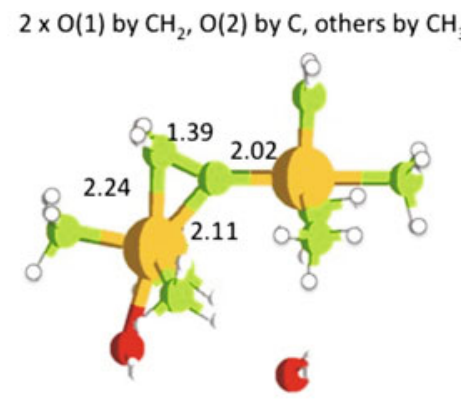

Mo-Mo 3.74

$2 \times \mathrm{O}$ (1) by $\mathrm{CH}_{2}, \mathrm{O}(2)$ by $\mathrm{CH}_{2}$, others by $\mathrm{CH}_{3}$

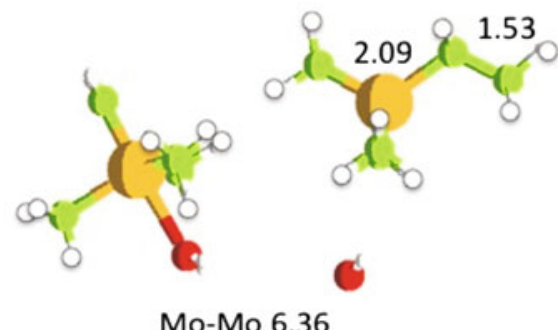

Mo-Mo 6.36
$2 \times \mathrm{O}(1)$ removed, $\mathrm{O}(2)$ by $\mathrm{C}$, others by $\mathrm{CH}_{3}$

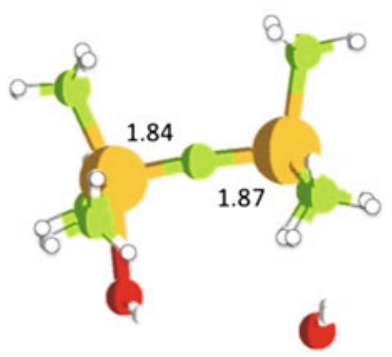

Mo-Mo 3.71

$2 \times \mathrm{O}(1)$ removed, $\mathrm{O}(2)$ by $\mathrm{CH}_{2}$, others by $\mathrm{CH}_{3}$

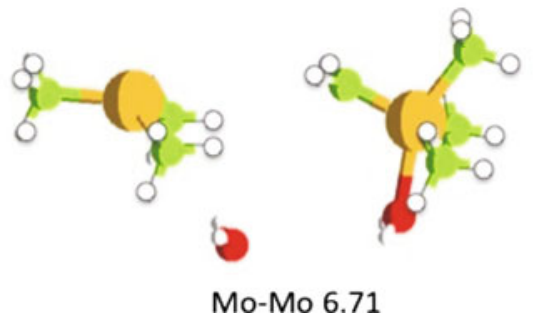


Table 2 Energy changes accompanying the process of $\mathrm{MoO}_{3}$ reduction by methane

\begin{tabular}{llllll}
\hline $\begin{array}{l}\mathrm{CH}_{2} \\
\text { replacing }\end{array}$ & $\mathrm{O}(1)$ & $\mathrm{O}(2)$ & $\begin{array}{l}\mathrm{O}(1), \\
\mathrm{O}(1)^{\mathrm{a}}\end{array}$ & $\begin{array}{l}\mathrm{O}(1), \\
\mathrm{O}(2)\end{array}$ & $\begin{array}{l}\mathrm{O}(1), \mathrm{O}(2), \\
\mathrm{O}(1)^{\mathrm{a}}\end{array}$ \\
\hline$\Delta \mathrm{E}[\mathrm{eV}]$ & 2.07 & 2.41 & 4.01 & 4.96 & 6.91
\end{tabular}

${ }^{a}$ Singly coordinate oxygen atom which occupies intermediate position between singly and doubly occupied site after vacancy formation-see [16]

13, 25]. It reacts with small clusters of molybdenum trioxide yielding surface (oxo)carbides and water.

Table 2 gathers the energy change accompanying the studied reaction:

$\mathrm{MoO}_{3}+y \mathrm{CH}_{4} \rightarrow \mathrm{MoO}_{3-y} \mathrm{C}_{y} \mathrm{H}_{2 y}+y \mathrm{H}_{2} \mathrm{O}$

according to the formula:

$$
\begin{aligned}
\Delta \mathrm{E}= & \mathrm{E}\left(\mathrm{MoO}_{3-y} \mathrm{C}_{y} \mathrm{H}_{2 y}\right)+y \mathrm{E}\left(\mathrm{H}_{2} \mathrm{O}\right)-\mathrm{E}\left(\mathrm{MoO}_{3}\right) \\
& -y \mathrm{E}\left(y \mathrm{CH}_{4}\right)
\end{aligned}
$$

Each of the calculated energies is positive, which means that the process of $\mathrm{MoO}_{3}$ reduction to yield (oxo)carbides is endoenergetic. This finding is consistent with the experimental conditions in which the process is observed (high temperature in range of $650-700{ }^{\circ} \mathrm{C}$ ) [1-8]. Moreover, it may be seen that there is no synergy between the amount of carbon already introduced to the system and the energetic cost of replacing oxygen atom by $\mathrm{CH}_{2}$, i.e., the cost of the investigated transformation is approximately doubled when two $\mathrm{CH}_{2}$ groups are replacing oxygen atoms with respect to the single substitution of $\mathrm{O}$ for $\mathrm{CH}_{2}$, etc.

\section{Conclusions}

In the present paper, an attempt to describe structural changes accompanying the formation of molybdenum (oxo)carbides form $\mathrm{MoO}_{3}$ has been made by considering species of different compositions resulting from the systematic replacement of oxygen by carbon or $\mathrm{CH}_{2}$ terminal groups. In bulk, the stability of single atom substituted structures is as follows: $\mathrm{O}(2)>\mathrm{O}(3)>\mathrm{O}(1)$. There is no direct correlation between the site of the introduced carbon atoms and the structure stability. It is found that the formation of $\mathrm{C}_{2}$ and $\mathrm{CO}$ groups is the stabilizing factor when the bulk structure is considered. These might be created without barrier, regardless the hindrances imposed by the lattice atoms. While the surface cluster is considered, the barrier-less formation of $\mathrm{C}_{2} \mathrm{H}_{2}$ and $\mathrm{CO}$ species is also observed. In general, both in bulk and at the surface, the C-containing species have tendency to aggregate. The thermodynamic considerations reveal that the reduction of molybdenum trioxide by methane is endoenergetic.
Acknowledgments This work was supported by the project EC 7th FP 2009-229183 NEXT-GTL "Innovative catalytic technologies \& materials for next gas to liquid processes."

Open Access This article is distributed under the terms of the Creative Commons Attribution License which permits any use, distribution, and reproduction in any medium, provided the original author(s) and the source are credited.

\section{References}

1. Xu Y, Bao X, Lin L (2003) Direct conversion of methane under nonoxidative conditions. J Catal 216(1-2):386-395

2. Ding W, Li S, Meitzner GD, Iglesia E (2000) Methane conversion to aromatics on $\mathrm{Mo} / \mathrm{H}-\mathrm{ZSM}$ 5: structure of molybdenum species in working catalysts. J Phys Chem B 105(2):506-513. doi: $10.1021 / \mathrm{jp} 0030692$

3. Zhang J-Z, Long MA, Howe RF (1998) Molybdenum ZSM-5 zeolite catalysts for the conversion of methane to benzene. Catal Today 44(1-4):293-300

4. Wang L, Tao L, Xie M, Xu G, Huang J, Xu Y (1993) Dehydrogenation and aromatization of methane under non-oxidizing conditions. Catal Lett 21(1):35-41. doi:10.1007/bf00767368

5. Wong S-T, Xu Y, Wang L, Liu S, Li G, Xie M, Guo X (1996) Methane and ethane activation without adding oxygen: promotional effect of W in Mo-W/HZSM-5. Catal Lett 38(1):39-43. doi:10.1007/bf00806897

6. Xu Y, Liu W, Wong S-T, Wang L, Guo X (1996) Dehydrogenation and aromatization of methane in the absence of oxygen on Mo/HZSM-5 catalysts before and after $\mathrm{NH}_{4} \mathrm{OH}$ extraction. Catal Lett 40(3):207-214. doi:10.1007/bf00815284

7. Shu Y, Ohnishi R, Ichikawa M (2002) Pressurized dehydrocondensation of methane toward benzene and naphthalene on $\mathrm{Mo} /$ HZSM-5 catalyst: optimization of reaction parameters and promotion by $\mathrm{CO}_{2}$ addition. $\mathrm{J}$ Catal 206(1):134-142. doi: 10.1006/jcat.2001.3481

8. Solymosi F, Szöke A, Cserényi J (1996) Conversion of methane to benzene over $\mathrm{Mo}_{2} \mathrm{C}$ and $\mathrm{Mo}_{2} \mathrm{C} / \mathrm{ZSM}-5$ catalysts. Catal Lett 39(3):157-161. doi:10.1007/bf00805576

9. Xu Y, Lin L (1999) Recent advances in methane dehydro-aromatization over transition metal ion-modified zeolite catalysts under non-oxidative conditions, vol 188, 1-2 edn. Elsevier Science, Amsterdam

10. Li Y, Liu L, Huang X, Liu X, Shen W, Xu Y, Bao X (2007) Enhanced performance of methane dehydro-aromatization on Mo-based HZSM-5 zeolite pretreated by $\mathrm{NH}_{4} \mathrm{~F}$, vol 8, 11th edn. Elsevier Science, Amsterdam

11. Aritani H, Shibasaki H, Orihara H, Nakahira A (2009) Methane dehydroaromatization over Mo-modified H-MFI for gas to liquid catalysts, vol 21, 6th edn. Elsevier Science, Amsterdam

12. Solymosi F, Szoeke A (1998) Conversion of ethane into benzene on $\mathrm{Mo}_{2} \mathrm{C} / \mathrm{ZSM}-5$ catalyst. Appl Catal A 166(1):225-235

13. Jiang H, Wang L, Cui W, Xu Y (1999) Study on the induction period of methane aromatization over Mo/HZSM-5: partial reduction of Mo species and formation of carbonaceous deposit. Catal Lett 57(3):95-102. doi:10.1023/a:1019087313679

14. Zheng H, Ma D, Bao X, Hu JZ, Kwak JH, Wang Y, Peden CHF (2008) Direct observation of the active center for methane dehydroaromatization using an ultrahigh field ${ }^{95}$ Mo NMR spectroscopy. J Am Chem Soc 130(12):3722-3723. doi:10.1021/ja7110916

15. Xu Y, Liu S, Guo X, Wang L, Xie M (1995) Methane activation without using oxidants over Mo/HZSM-5 zeolite catalysts. Catal Lett 30(1):135-149. doi:10.1007/bf00813680 
16. Tokarz-Sobieraj R, Grybos R, Witko M, Hermann K (2004) Oxygen sites at molybdena and vanadia surfaces: energetics of the re-oxidation process. Collect Czech Chem Commun 69(1):121-140. doi:10.1135/cccc20040121

17. Shi X-R, Wang S-G, Wang H, Deng C-M, Qin Z, Wang J (2009) Structure and stability of $\beta-\mathrm{Mo}_{2} \mathrm{C}$ bulk and surfaces: a density functional theory study. Surf Sci 603(6):851-858

18. Shi X-R, Wang J, Hermann K (2010) CO and NO adsorption and dissociation at the $\beta-\mathrm{Mo}_{2} \mathrm{C}(0001)$ surface: a density functional theory study. J Phys Chem C 114(32):13630-13641. doi:10.1021/ jp912036z

19. Tokarz-Sobieraj R, Hermann K, Witko M, Blume A, Mestl G, Schlogl R (2001) Properties of oxygen sites at the $\mathrm{MoO}_{3}(010)$ surface: density functional theory cluster studies and photoemission experiments. Surf Sci 489(1-3):107-125

20. Witko M, Tokarz-Sobieraj R (2007) Electronic properties of the active sites present at the (011) surface of MoO2. Adsorpt Sci Technol 25(8):583-596

21. Zhou T, Liu A, Mo Y, Zhang H (2000) Sequential mechanism of methane dehydrogenation over metal (Mo or W) oxide and carbide catalysts. J Phys Chem C 104(19):4505-4513. doi:10.1021/ jp9929622

22. Handzlik J (2010) Computational study of the properties and metathesis activity of Mo methylidene species in HZSM-5 zeolite. J Mol Catal A 316(1-2):106-111

23. Zhou D, Zhang Y, Zhu H, Ma D, Bao X (2007) The Structure, stability, and reactivity of Mo-oxo species in H-ZSM5 zeolites: density functional theory study. J Phys Chem C 111(5):20812091. doi:10.1021/jp0640934

24. Fu G, Xu X, Lu X, Wan H (2005) Mechanisms of methane activation and transformation on molybdenum oxide based catalysts. J Am Chem Soc 127(11):3989-3996. doi:10.1021/ ja0441099

25. Solymosi F, Cserényi J, Szöke A, Bánsági T, Oszkó A (1997) Aromatization of methane over supported and unsupported Mobased catalysts. J Catal 165(2):150-161

26. Kresse G, Hafner J (1994) Ab initio molecular-dynamics simulation of the liquid-metal amorphous-semiconductor transition in germanium. Phys Rev B 49(20):14251

27. Kresse G, Furthmüller J (1996) Efficient iterative schemes for ab initio total-energy calculations using a plane-wave basis set. Phys Rev B 54(16):11169
28. Kresse G, Furthmüller J (1996) Efficiency of ab initio total energy calculations for metals and semiconductors using a planewave basis set. Comput Mater Sci 6(1):15-50. doi:10.1016/09270256(96)00008-0

29. Perdew JP, Chevary JA, Vosko SH, Jackson KA, Pederson MR, Singh DJ, Fiolhais C (1992) Atoms, molecules, solids, and surfaces: applications of the generalized gradient approximation for exchange and correlation. Phys Rev B 46(11):6671

30. Perdew JP, Wang Y (1992) Accurate and simple analytic representation of the electron-gas correlation energy. Phys Rev B 45(23): 13244

31. Blöchl PE (1994) Projector augmented-wave method. Phys Rev B 50(24): 17953

32. Kresse G, Joubert D (1999) From ultrasoft pseudopotentials to the projector augmented-wave method. Phys Rev B 59(3):1758

33. Kihlborg L (1963) Least squares refinement of the crystal structure of molybdenum trioxide. Arkiv foer Kemi 21:357-364

34. Witko M, Tokarz-Sobieraj R (2004) Surface oxygen in catalysts based on transition metal oxides-What can we learn from cluster DFT calculations? Catal Today 91-2:171-176. doi: 10.1016/j.cattod.2004.03.029

35. TURBOMOLE V6.3 (2011) adoUoKa, Forschungszentrum Karlsruhe GmbH-, TURBOMOLE GmbH saf. http://www.turbo mole.com. Accessed March 2011

36. Dirac PAM (1929) Quantum mechanics of many-electron systems. Proc R Soc Lond Ser A 123(792):714-733. doi: 10.1098/rspa.1929.0094

37. Slater JC (1951) A simplification of the Hartree-Fock method. Phys Rev 81(3):385-390

38. Perdew JP, Burke K, Ernzerhof M (1996) Generalized gradient approximation made simple. Phys Rev Lett 77(18):3865-3868

39. Eichkorn K, Treutler O, Öhm H, Häser M, Ahlrichs R (1995) Auxiliary basis sets to approximate coulomb potentials. Chem Phys Lett 240:283-289

40. Eichkorn K, Weigend F, Treutler O, Ahlrichs R (1997) Auxiliary basis sets for main row atoms and transition metals and their use to approximate Coulomb potentials. Theor Chem Acc 97:119124

41. Schäfer A, Huber C, Ahlrichs R (1994) Fully optimized contracted gaussian basis sets of triple zeta valence quality for atoms Li to Kr. J Chem Phys 100(8):5829-5835 